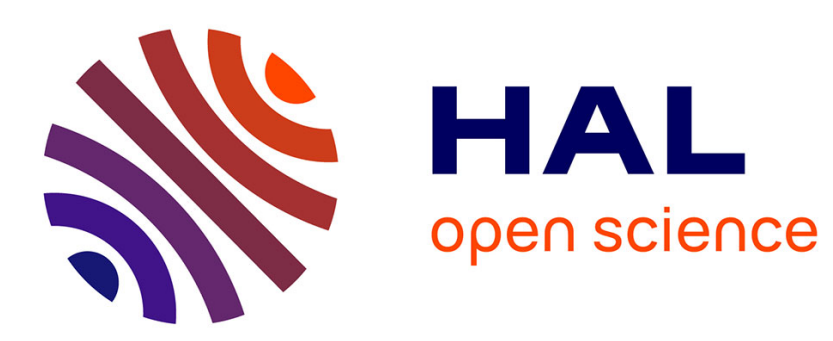

\title{
Characterisation of carbon blacks produced by solar thermal dissociation of methane
}

Sylvain Rodat, Stéphane Abanades, Eusebiu Grivei, Giorgos Patrianakos, Alexandra Zygogianni, Athanasios Konstandopoulos, Gilles Flamant

\section{To cite this version:}

Sylvain Rodat, Stéphane Abanades, Eusebiu Grivei, Giorgos Patrianakos, Alexandra Zygogianni, et al. Characterisation of carbon blacks produced by solar thermal dissociation of methane. Carbon, 2011, 49 (9), pp.3084-3091. 10.1016/j.carbon.2011.03.030 . hal-02567206

\section{HAL Id: hal-02567206 \\ https://hal.science/hal-02567206}

Submitted on 12 May 2020

HAL is a multi-disciplinary open access archive for the deposit and dissemination of scientific research documents, whether they are published or not. The documents may come from teaching and research institutions in France or abroad, or from public or private research centers.
L'archive ouverte pluridisciplinaire HAL, est destinée au dépôt et à la diffusion de documents scientifiques de niveau recherche, publiés ou non, émanant des établissements d'enseignement et de recherche français ou étrangers, des laboratoires publics ou privés. 
Characterisation of carbon blacks produced by solar thermal dissociation of methane

Sylvain Rodat ${ }^{*}$, a, Stéphane Abanades ${ }^{\mathrm{a}}$, Eusebiu Grivei ${ }^{\mathrm{b}}$, Giorgos Patrianakos ${ }^{\mathrm{c}}$, Alexandra Zygogianni $^{\mathrm{c}}$, Athanasios G. Konstandopoulos ${ }^{\mathrm{c}}$ and Gilles Flamant ${ }^{\mathrm{a}}$

${ }^{a}$ PROMES-CNRS Laboratory, 7 rue du four solaire, 66120 Font-Romeu, France

${ }^{\mathrm{b}}$ MATERIA NOVA Av. N. Copernic, 1. 7000 Mons, Belgium

${ }^{c}$ Aerosol and Particle Technology Laboratory (APTL), Chemical Process Engineering Research Institute (CPERI), Centre for Research and Technology Hellas (CERTH), $6^{\text {th }} \mathrm{km}$ Charilaou - Thermi Road, Thermi 57001, Thessaloniki, Greece

Solar methane dissociation appears as a possible route toward a hydrogen-based economy. The competitiveness of the process strongly depends on the carbon black properties and economic value. At CNRS-PROMES, a $50 \mathrm{~kW}$ tubular solar reactor was developed to produce carbon black and hydrogen from methane. The reaction was carried out in a graphite receiver crossed by seven graphite tubes heated up by concentrated solar radiations at the 1 MW CNRS solar furnace. The temperatures ranged between $1608 \mathrm{~K}$ and $1928 \mathrm{~K}$ and the methane flow-rates varied from 10.5 to $21 \mathrm{NL} / \mathrm{min}$. Total methane dissociation was reached with hydrogen yield higher than $80 \%$ and the carbon yield was drastically affected by the acetylene by-product. The carbon samples were analysed in detail and their properties were

\footnotetext{
* Corresponding author.

Tel: +33468307731

Fax: +33468302940

E-mail address: srodat@gmail.com (S. Rodat)
} 
compared to a commercial conductive grade carbon black. Transmission electron microscopy showed primary particles of $10-70 \mathrm{~nm}$ diameter. The crystallinity of the samples was characterised by Raman spectroscopy. It was also possible to correlate the specific surface area with the reaction temperature and with the concentrations of residual methane and of the acetylene by-product. The resistivity and the structure of the agglomerates were determined by simultaneous measurements of the conductivity and the density under compression.

\section{Introduction}

Carbon black is a well-known additive for rubbers, inks, conductive polymers and batteries. It has many applications depending on its physical and chemical properties. It is mainly produced by the furnace process [1]. The world production is about $10 \mathrm{Mt}$ per year [2]. This process releases $5.7 \mathrm{~kg} \mathrm{CO}$ - equivalent per $\mathrm{kg}$ of carbon black [3] and thus contributes significantly to global warming. Typical yields of carbon black, depending on feedstock quality, is about 0.5 ton per ton of feedstock (for non porous carbons) and values as low as 0.35 are also reported (the other part being transformed into $\mathrm{CO}_{2}$ and $\mathrm{H}_{2} \mathrm{O}$ ) [4]. In order to avoid $\mathrm{CO}_{2}$ emission, the heat supply should be achieved by non-conventional processes (no combustion). Consequently, alternative solutions have to be investigated. Plasma reactors have been proposed [5-7]. However, this process requires electricity, i.e. high-grade energy, whereas solar high temperature heat could be used. Solar methane dissociation was studied with two possible reactor configurations: either direct heating reactors with particle seeding or indirect heating reactors. In the case of seeded reactors, particles catalyse the reaction but carbon blacks grow on the catalyst surface leading to a blocking of active sites [8-9]. In this paper, the solar methane dissociation is proposed in an indirect heating reactor. The solar reactor design and the experimental results about chemical reactor performances were 
published previously in [10] and this paper focuses on the thorough analysis of the carbon black properties produced in the solar reactor. Little work has been proposed in the literature concerning carbon black properties in case of solar methane dissociation. XRD and microscopy analysis were essentially employed $[3,11]$ but this kind of characterisation is not sufficient. Brunauer, Emmett and Teller method (BET), Raman spectroscopy, evaluation of carbon blacks by the assessment of pressure to volume relation along with conductivity measurements have to be carried out. The specific surface area is an important property of carbon blacks that clearly influences the end-use application [12]. Raman spectroscopy permits to estimate the crystallinity of nanostructured carbons [13]. Also, the curves giving the conductivity of a carbon black sample versus density can be considered as an ideal way to characterize the so-called conductive blacks [14]. In a first part, the experimental set-up for solar methane dissociation will be briefly described, and then the carbon black properties will be discussed with respect to Transmission Electron Microscopy (TEM) imaging, Raman spectroscopy, specific surface area measurements (BET) and tests under compression. Comparison with commercial samples (conductive carbon black E250G from Timcal company $^{1}$ ) and correlations between solar reactor operating conditions and carbon black properties are also addressed, bringing new information for potential applications.

\section{Experimental}

\subsection{Experimental set-up}

The solar reactor for methane dissociation is displayed in Figure 1. It is composed of a cubic graphite cavity (about $40 \mathrm{~cm}$ side) serving as radiant absorber. It is crossed by 7 horizontal tubes ( $800 \mathrm{~mm}$ length, $26 \mathrm{~mm}$ o.d., $18 \mathrm{~mm}$ i.d.) heated up by both in-coming concentrated

\footnotetext{
${ }^{1}$ Timcal Ltd. Technical Data Sheet. ENSACO 250G. Conductive Carbon Black. Version 02/09. Bodio, Switzerland, http://www.timcal.com.
} 
solar radiations and IR radiations from the hot cavity walls. The concentrated solar power entered the cavity via a $13 \mathrm{~cm}$-diameter opening in the water-cooled front face. A domed quartz window and an aluminium box separate the graphite absorber from the oxidizing atmosphere. Methane thermal dissociation occurs in the tubes. Additional information can be found in reference [10].

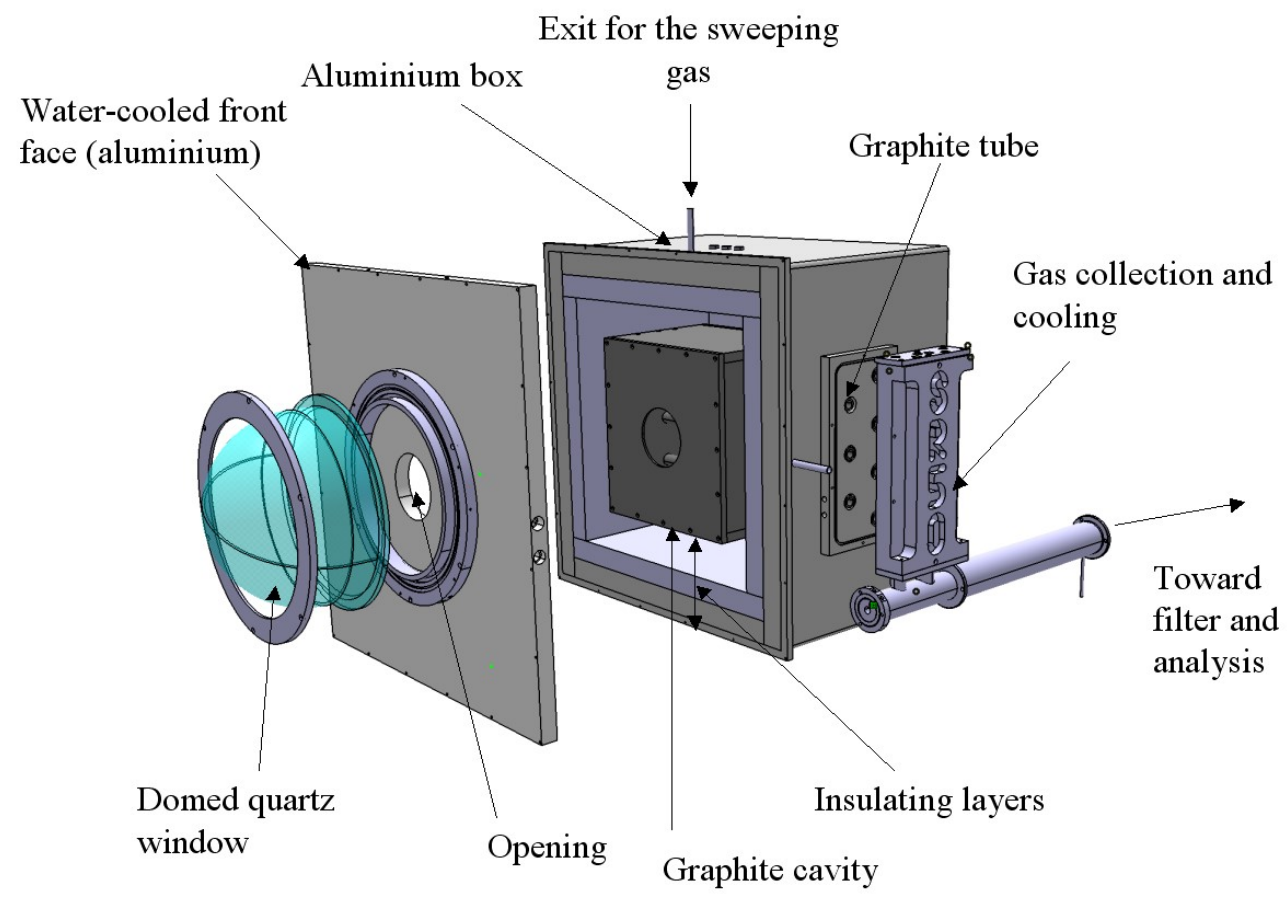

Figure 1: $50 \mathrm{~kW}$ solar reactor

The first experimental step was the heating of the reactor under an argon flow in the tubes. Once the desired temperature reached, the mixture of argon and methane was injected with a controlled composition. Two mass-flow controllers were dedicated to each tube to control accurately the $\mathrm{Ar}$ and $\mathrm{CH}_{4}$ flow-rates. The temperature was measured by a solar blind optical pyrometer (wavelength: $5.14 \mu \mathrm{m}$ ) pointing toward the outer wall of a graphite tube inside the cavity through a $\mathrm{CaF}_{2}$ window. Pt-Rh thermocouples were also used. At the exit of each tube, the exhaust gas-solid flows were collected, cooled and mixed together. The solid and gaseous products were cooled down and flowed through a filter bag to separate carbon particles. The pressure was monitored by pressure sensors placed at each tube entrance and was regulated thanks to the use of a vacuum pump (absolute operating pressure of about $40 \mathrm{kPa}$ ). The 
filtered gas was then analyzed to determine the gas composition. A continuous analyzer permitted to monitor the concentration of $\mathrm{H}_{2}$ and $\mathrm{CH}_{4}$. The methods used for $\mathrm{H}_{2}$ and $\mathrm{CH}_{4}$ analysis were thermal conductivity and non-dispersive infrared detections, respectively. A gas chromatograph also measured online the outlet concentrations of $\mathrm{CH}_{4}, \mathrm{C}_{2} \mathrm{H}_{6}, \mathrm{C}_{2} \mathrm{H}_{4}, \mathrm{C}_{2} \mathrm{H}_{2}$, and $\mathrm{H}_{2}$. The chromatograph (Varian CP 4900) was equipped with 2 columns: MolSieve 5A PLOT

for $\mathrm{H}_{2}$ and $\mathrm{CH}_{4}$, and PoraPLOT $\mathrm{U}$ for light hydrocarbons $\left(\mathrm{C}_{2} \mathrm{H}_{\mathrm{y}}\right)$. The chromatography analysis was based on thermal conductivity detection and the carrier gas was argon, also used as buffer gas during methane cracking experiments. The experiments were carried out at the 1 MW solar furnace (CNRS-PROMES, Odeillo, France). This furnace is composed of a field of 63 heliostats for full power $\left(45 \mathrm{~m}^{2}\right.$ per heliostat) and of a parabolic concentrator $\left(1830 \mathrm{~m}^{2}\right)$ delivering up to 9000 suns at the focal plane. During experiments, only a fraction of the parabola was used by limiting the number of heliostats tracking the sun and by using a shutter. The resulting power density varies in the range $1.7-2.8 \mathrm{MW} . \mathrm{m}^{-2}$.

\subsection{Experimental conditions}

The experimental conditions tested are summarized in Table 1. Total methane dissociation was reached with a hydrogen yield greater than $80 \%$. The carbon yield is defined as the ratio between the quantity of solid carbon obtained (calculated from a mass balance on the gaseous species) and the initial carbon content in the feed:

$$
\mathrm{Y}_{\mathrm{C}}=\frac{\mathrm{F}_{0}, \mathrm{CH}_{4}-\left(\mathrm{F} \cdot \mathrm{yCH}_{4}+2 \cdot \mathrm{F}_{2} \mathrm{yC}_{2} \mathrm{H}_{2}+2 \cdot \mathrm{F}_{2} \cdot \mathrm{y}_{2} \mathrm{H}_{4}+2 \cdot \mathrm{F}_{2} \mathrm{yC}_{2} \mathrm{H}_{6}\right)}{\mathrm{F}_{0}, \mathrm{CH}_{4}}
$$

where $\mathrm{F}_{0, \mathrm{CH} 4}$ is the inlet molar flow-rate of $\mathrm{CH}_{4}, \mathrm{y}_{\mathrm{i}}$ is the mole fraction of species $\mathrm{i}$, and $\mathrm{F}$ is the total outlet gas flow-rate (including argon as buffer gas) obtained from: 
$\mathrm{F}=\frac{\mathrm{F}_{\mathrm{Ar}}}{1-\left(\mathrm{yCH}_{4}+\mathrm{yH}_{2}+\mathrm{yC}_{2} \mathrm{H}_{2}+\mathrm{yC}_{2} \mathrm{H}_{4}+\mathrm{yC}_{2} \mathrm{H}_{6}\right)}$.

$\mathrm{F}_{\mathrm{Ar}}$ is the molar flow-rate of Ar. In equations (1) and (2), polycyclic aromatic hydrocarbons are neglected.

It was strongly affected by the amount of by-product acetylene. Nevertheless, in each experiment, the mass of carbon black recovered in the filter (given in Table 1) was high enough to perform representative sample characterizations, regardless of the experimental conditions. The carbon black deposited on the walls was recovered separately and was not mixed with the carbon black recovered in the filter.The samples from the filter were analyzed and the results are presented below.

Table 1: Summary of the experimental conditions tested (pressure is related to conditions inside the reaction tubes)

\begin{tabular}{cccccccccc}
\hline Run & $\begin{array}{c}\text { Ar } \\
\text { (NL/min) }\end{array}$ & $\begin{array}{c}\mathbf{C H}_{4} \\
(\mathbf{N L} / \mathbf{m i n})\end{array}$ & $\begin{array}{c}\mathbf{C H}_{4} \\
\text { mole } \\
\text { fraction }\end{array}$ & $\begin{array}{c}\text { Pressure } \\
\mathbf{( P a )}\end{array}$ & $\begin{array}{c}\text { Tpyrometer } \\
\mathbf{( K )}\end{array}$ & $\begin{array}{c}\text { Residence } \\
\text { time } \\
\mathbf{( s )}\end{array}$ & $\begin{array}{c}\text { Curation } \\
\text { (min) }\end{array}$ & $\begin{array}{c}\text { Carbon } \\
\text { yield }\end{array}$ & $\begin{array}{c}\text { mass } \\
\text { collected } \\
\text { in the } \\
\text { filter (g) }\end{array}$ \\
\hline 1 & 31.5 & 10.5 & 0.25 & 43000 & 1608 & 0.070 & 72 & 0.43 & 54.4 \\
\hline 2 & 31.5 & 10.5 & 0.25 & 46000 & 1693 & 0.071 & 63 & 0.50 & 77.8 \\
\hline 3 & 31.5 & 10.5 & 0.25 & 43000 & 1778 & 0.063 & 24 & 0.50 & 13.9 \\
\hline 4 & 31.5 & 10.5 & 0.25 & 42000 & 1793 & 0.061 & 33 & 0.47 & 24.8 \\
\hline 5 & 31.5 & 10.5 & 0.25 & 42000 & 1928 & 0.057 & 57 & 0.63 & 72.7 \\
\hline 6 & 49 & 21 & 0.3 & 47000 & 1698 & 0.043 & 46 & 0.41 & 53.0 \\
\hline 7 & 21 & 21 & 0.5 & 41000 & 1798 & 0.059 & 25 & 0.49 & 41.1 \\
\hline 8 & 49 & 21 & 0.3 & 43000 & 1808 & 0.037 & 53 & 0.42 & 106.5 \\
\hline 9 & 49 & 21 & 0.3 & 45000 & 1873 & 0.038 & 33 & 0.45 & 69.1 \\
\hline
\end{tabular}

\section{Carbon black properties}

\subsection{Particle morphology and crystallinity: Raman spectroscopy and TEM imaging}


Raman scattering is a unique characterization tool for nanostructured carbon materials, such as carbon black, because of its ability to determine the structural basis for the emission and propagation of optical phonons, which thus leads to information regarding the nanostructure of these materials $[13,15,16]$ such as the degree of graphitization and crystallite size. Furthermore, TEM is a very useful tool for directly observing the aggregate morphology of particulate materials, such as carbon black, as well as the primary particle nanostructure in the case of high resolution TEM. Four solar particle samples and one sample of the commercial carbon black E250G were characterized using Raman spectroscopy and high resolution TEM. The four solar samples were obtained, respectively, from experiments 1, 2, 3 and 5, corresponding to four different reactor temperatures but approximately similar gas residence times in the reactor.

The Raman spectra of the samples were recorded in the $100-3200 \mathrm{~cm}^{-1}$ region using a Renishaw inVia Reflex micro-Raman spectrometer equipped with an air-cooled Argon ion laser and CCD detector. A $514.5 \mathrm{~nm}(50 \mathrm{~mW})$ laser line was used as an excitation source. The samples were examined at room temperature. Backscattering illumination and collection of the scattered light were made through a Leica confocal microscope. The diameter of the laser spot on the sample surface was $1 \mu \mathrm{m}$ for the fully focused laser beam and $40 \mu \mathrm{m}$ for the fully defocused beam. A five band fitting procedure [15] was applied to the Raman spectra (Lorentzian shape for $\mathrm{D}_{1}, \mathrm{D}_{2}, \mathrm{D}_{4}$ and $\mathrm{G}$ bands, Gaussian shape for the $\mathrm{D}_{3}$ band). The integrated area ratio $A_{\mathrm{D} 1} / A_{\mathrm{G}}$ of the $\mathrm{D}_{1}$ and $\mathrm{G}$ bands was interpreted as a measure of the crystallinity of the primary particles, in other words as a graphitization index (decreasing ratio corresponding to increasing graphitization), while an estimation of the average crystallite length (a parameter influencing the applicative properties of the material [17]) was derived from the peak intensity ratio $I_{\mathrm{D} 1} / I_{\mathrm{G}}$ of the same bands using the correlation of Knight and White for a $514.5 \mathrm{~nm}$ laser $[13,18,19]$ : 


$$
L_{\mathrm{a}}=4.4\left(\frac{I_{\mathrm{D} 1}}{I_{\mathrm{G}}}\right)^{-1}
$$

The results from Raman spectroscopy are summarized in Table 2 where it can be seen that all samples exhibit a similar degree of graphitization $\left(A_{\mathrm{D} 1} / A_{\mathrm{G}}\right)$ and similar average crystallite lengths $\left(L_{\mathrm{a}}\right)$. In the case of the solar particles, therefore, the $320 \mathrm{~K}$ variation in reactor temperature does not appear to have significantly affected the crystallinity, apart for the high temperature sample 5 which is slightly more graphitic.

Table 2: Raman spectroscopy results

\begin{tabular}{lllll}
\hline Sample & $\begin{array}{l}\text { Temperature } \\
\text { of reactor (K) }\end{array}$ & $A_{\mathrm{D} 1} / A_{\mathrm{G}}$ & $I_{\mathrm{D} 1} / I_{\mathrm{G}}$ & $L_{\mathrm{a}}(\mathrm{nm})$ \\
\hline E250G & - & 3.7 & 1.6 & 2.8 \\
Run 1 & 1608 & 3.8 & 1.6 & 2.8 \\
Run 2 & 1693 & 3.6 & 1.6 & 2.7 \\
Run 3 & 1778 & 3.6 & 1.6 & 2.7 \\
Run 5 & 1928 & 3.4 & 1.7 & 2.6 \\
\hline
\end{tabular}

TEM analysis was performed using a high-resolution JEOL JEM 2011 microscope. Prior to imaging, the powder samples were de-agglomerated by sonication in a high purity isopropanol solution in order to isolate the aggregates as much as possible. During imaging, the copper grid was browsed in order to identify, by visual inspection, the various 
morphologies exhibited by the particles, and to qualitatively estimate which of these were dominant or exceptional in the population. Images were subsequently taken of particles whose morphology was found to be representative of the dominant morphologies observed, combining where possible two or more different particle morphologies in the same image for contrast. Images were also taken of exceptional particle morphologies in order to consider their possible origin.

TEM images of particles having morphologies that are representative of the dominant morphologies observed in each of the samples analyzed are shown in Figures 2 - 8. On the basis of the adopted TEM analysis methodology, qualitative observations and conclusions derived from visual inspection of these figures apply, in the most part, to all the particles in the respective sample. Inspection of Figures $2-7$ reveals greater variability in the primary particle size of the solar aggregates compared to the commercial aggregates; nevertheless, the fractal structure of the solar aggregates and the commercial aggregates appears to be similar. It is also interesting to note that in the case of the solar samples, aggregates consisting entirely of smaller primary particles or larger primary particles are present in the same sample (Figures 4 and 6), as are aggregates consisting of various primary particle sizes (Figure 7); however, in the case of the commercial sample, greater uniformity in primary particle size is observed (Figure 2). This is indicative of the existence of an extensive reaction boundary layer in the solar reactor, which results in the production of aggregates of different age and also of mixed age. Indeed, the solar reactor consists of a number of reactor tubes of large aspect ratio (length to diameter ratio); the flow in the tubes is laminar (no turbulent mixing) and a reaction boundary layer develops along the irradiated portion of the tubes [10]. Particles formed at the beginning of the reaction boundary layer are subject to significant growth via heterogeneous reaction on their surface and aggregation with smaller, newly formed particles; however, this does not apply as much to particles formed further along the reaction boundary 
layer. TEM can also reveal the length of the crystallites in the primary particles; for example, visual inspection of the primary particles from the sample from Run 5 in Figure 8 indicates crystallite lengths in the range of $1-5 \mathrm{~nm}$ approximately. However, a statistical image analysis, sampling several primary particles from each sample, would be necessary in order to verify the crystallite lengths estimated from Raman spectroscopy.

Figure 2: TEM image of representative commercial E250G particles.

Figure 3: TEM image of representative solar particles from run 1, produced at $1608 \mathrm{~K}$. 
Figure 4: TEM image of representative solar particles from run 2, produced at $1693 \mathrm{~K}$.

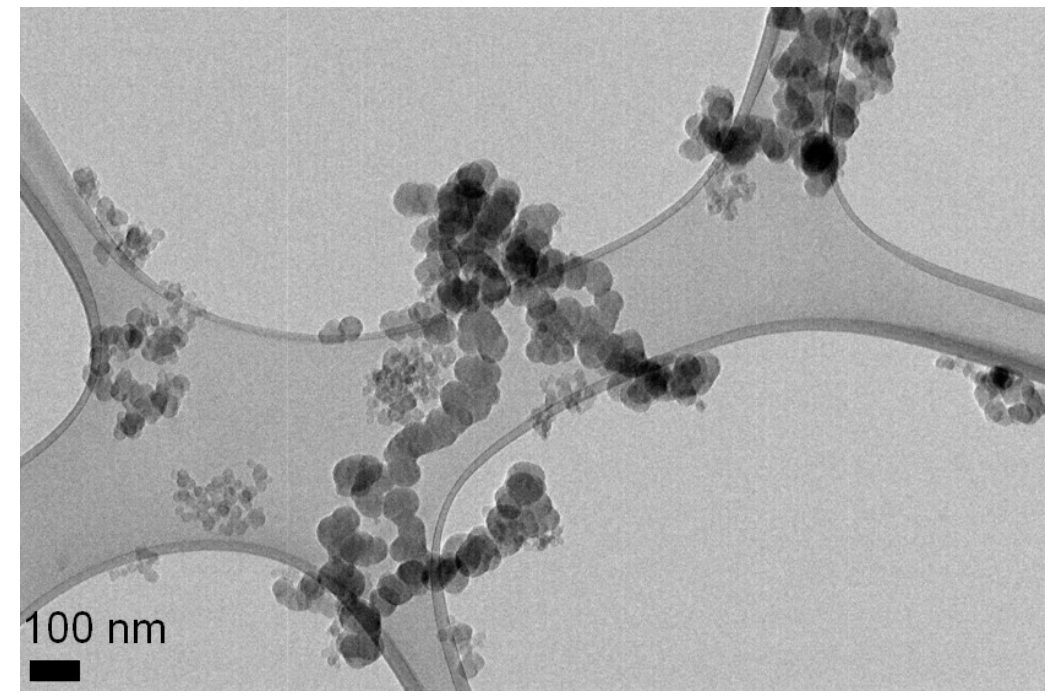

Figure 5: TEM image of representative solar particles from run 3, produced at $1778 \mathrm{~K}$. 
Figure 6: TEM image of representative solar particles from run 5, produced at $1928 \mathrm{~K}$.

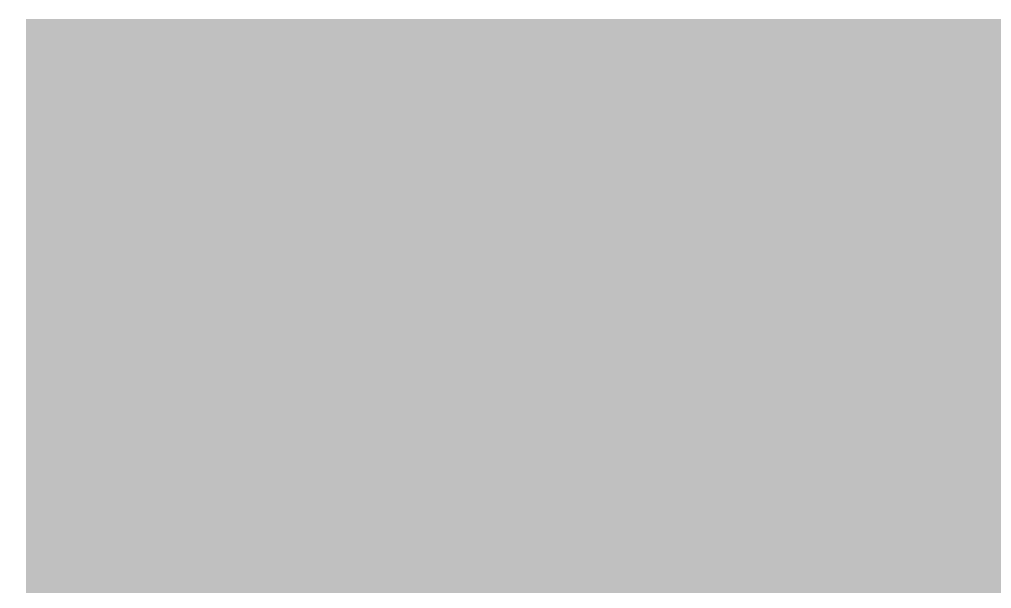

Figure 7: TEM image of representative solar particles from run 5, produced at $1928 \mathrm{~K}$. 


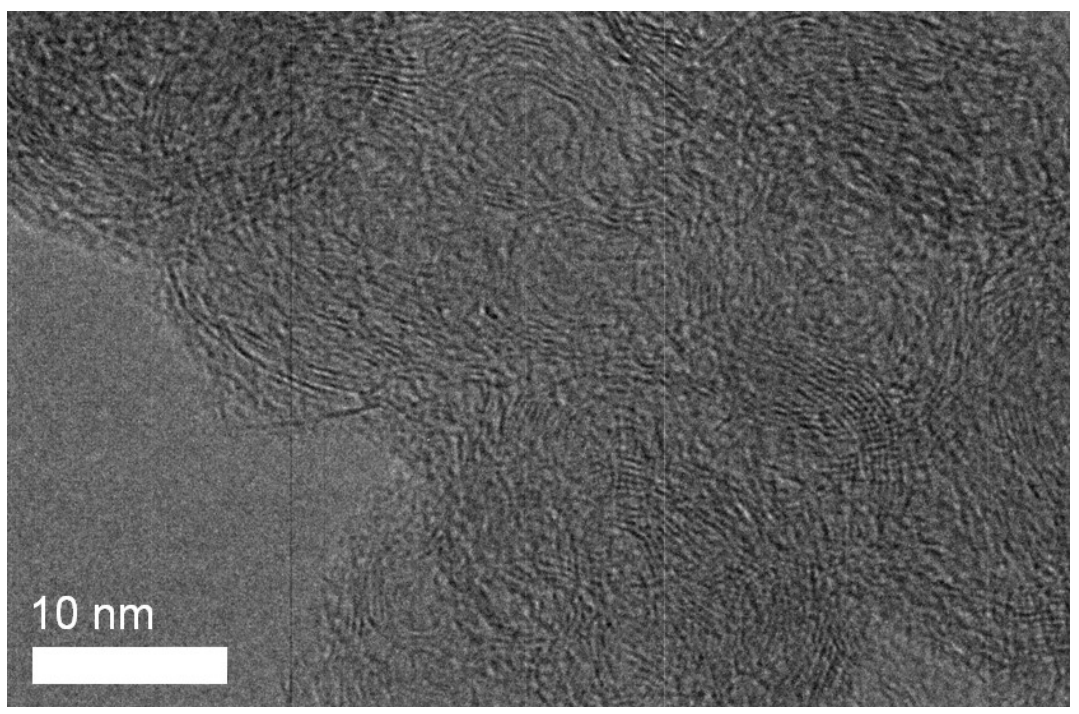

Figure 8: High magnification TEM image of representative solar primary particles from run 5 , produced at $1928 \mathrm{~K}$.

\subsection{Specific surface area: BET measurements}

The specific surface area of the samples was evaluated with the BET method. The measurement accuracy is $+/-1 \mathrm{~m}^{2} / \mathrm{g}$. The results obtained are reported in Figure 9. The specific surface area can reach $100 \mathrm{~m}^{2} / \mathrm{g}$ and increases when increasing the reactor temperature. The higher the methane flow-rate, the smaller the specific surface area. According to the EMSA (Electron Microscope Surface Area) formula, a specific surface area of $100 \mathrm{~m}^{2} / \mathrm{g}$ corresponds to a mean particle diameter of $33 \mathrm{~nm}$.

$$
S=6000 /\left(\rho . d_{p}\right)
$$

with $\mathrm{S}$ the specific surface area $\left(\mathrm{m}^{2} / \mathrm{g}\right), \rho$ the carbon black density $\left(=1.8 \mathrm{~g} / \mathrm{cm}^{3}\right)$ and $\mathrm{d}_{\mathrm{p}}$ the mean particle diameter $(\mathrm{nm})$. The assumption behind this formula is that the particles are not porous (indeed, there is no oxidizing treatment) so that the specific surface area determined from the BET method can be ascribed to the specific surface area S of spherical particles with a mean diameter $d_{p}$. Carbon black with EMSA ranging from 10 to $140 \mathrm{~m}^{2} / \mathrm{g}$ are notably used 
for tyres; for pigment application, very fine particles are required $(9-16 \mathrm{~nm})$ [20]. The BET of the conductive grade $\mathrm{E} 250 \mathrm{G}$ is $65 \mathrm{~m}^{2} / \mathrm{g}$.

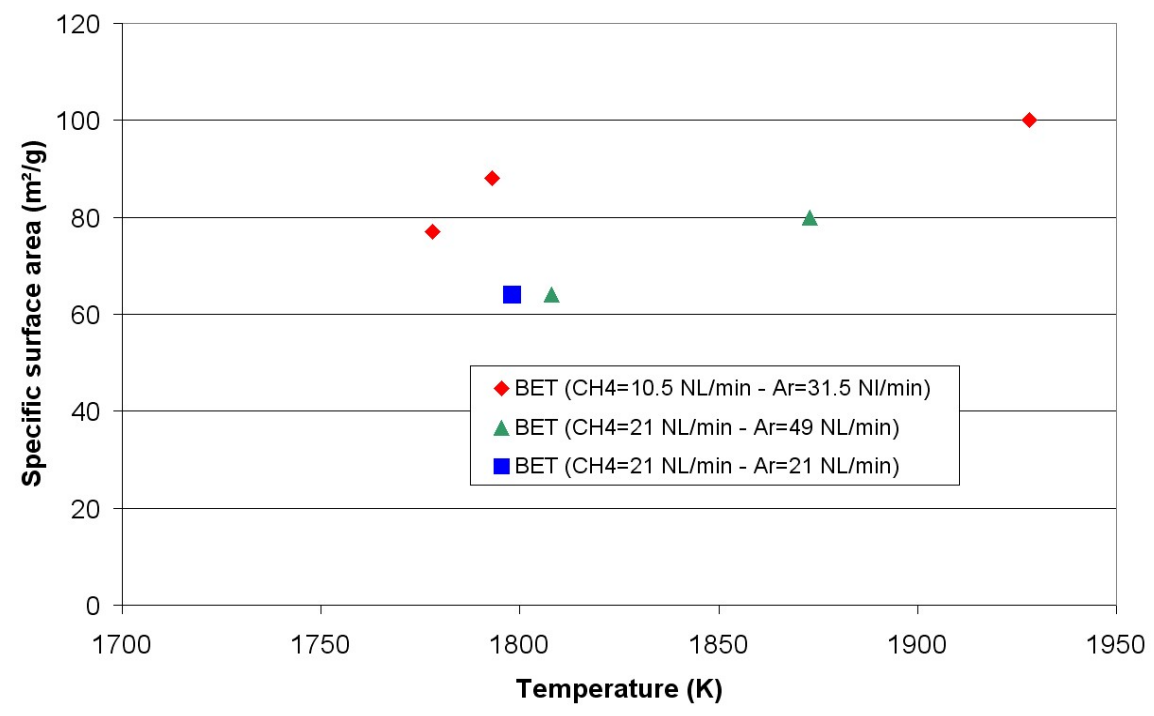

Figure 9: Specific surface area of carbon blacks as a function of the reactor temperature

The specific surface area can also be correlated with the residual concentration of methane (Figure 10) or acetylene (not shown) in the outlet gas. The trend shows that the specific surface area increases when the residual concentration of $\mathrm{CH}_{4}$ decreases. Let us note that $\mathrm{CH}_{4}$ concentration at the reactor outlet decreases with a temperature increase. Also, a similar trend is obtained when the $\mathrm{C}_{2} \mathrm{H}_{2}$ off-gas concentration decreases. In conclusion, there is a strong dependence of the specific surface area on the reactor temperature. Increasing the temperature results in an increase of the nucleation rate, which leads to smaller particles with a higher specific surface area [21]. 


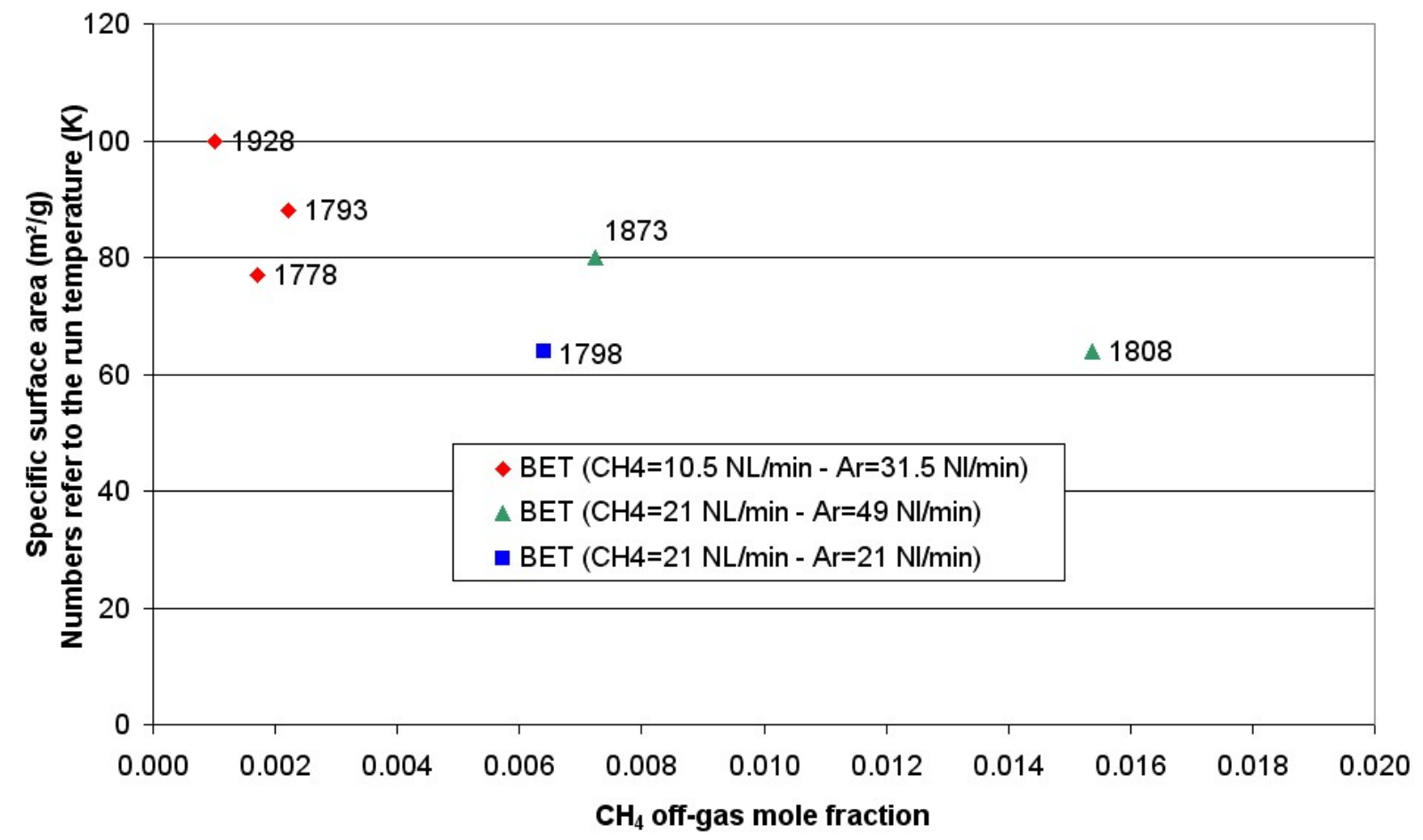

Figure 10: Specific surface area of carbon blacks as a function of the off-gas methane concentration

\subsection{Structure and conductivity: tests under compression}

The carbon black structure refers to the three-dimensional organization of the carbon black. A carbon black is defined as a high structure carbon black (numerous catenary agglomerates) or as a low structure carbon black. The present work considers the void-volume technique under a broader angle addressed in [14]. The evolution of the volume of a given amount of carbon black subjected to increasing compression as well as the evolution of the electrical resistivity is recorded and analysed. The structure can be evaluated by measuring the mechanical work required to bring a carbon black sample to a given density [14] (Figure 11). The accuracy for both mechanical work and resistivity is $+/-2 \%$ of the measurement. The slopes of the curves increase with carbon black structure. Indeed, high structure blacks require more energy to increase their apparent density. However, the curves of the mechanical energy versus density 
approach a linear behaviour for a given carbon black, which means that the amount of energy required to increase the apparent density is constant over the range of pressure applied. Thus, for E250G, an energy of $160 \mathrm{~kg} . \mathrm{cm}$ is required to reach $0.9 \mathrm{~g} / \mathrm{cm}^{3}$ whereas only $105 \mathrm{~kg} . \mathrm{cm}$ is required to reach the same density for the carbon black obtained at 1928K. E250G has a higher structure than the carbon black obtained at the highest temperature but this last sample approaches the behaviour of the commercial reference. This is confirmed by DiButyl Pthalate Absorption measurements (DBPA). The DBPA of E250G is $190 \mathrm{~mL} / 100 \mathrm{~g}$ whereas it is 144 $\mathrm{mL} / 100 \mathrm{~g}$ for the sample produced at $1928 \mathrm{~K}$. The higher the DBPA, the higher the structure.

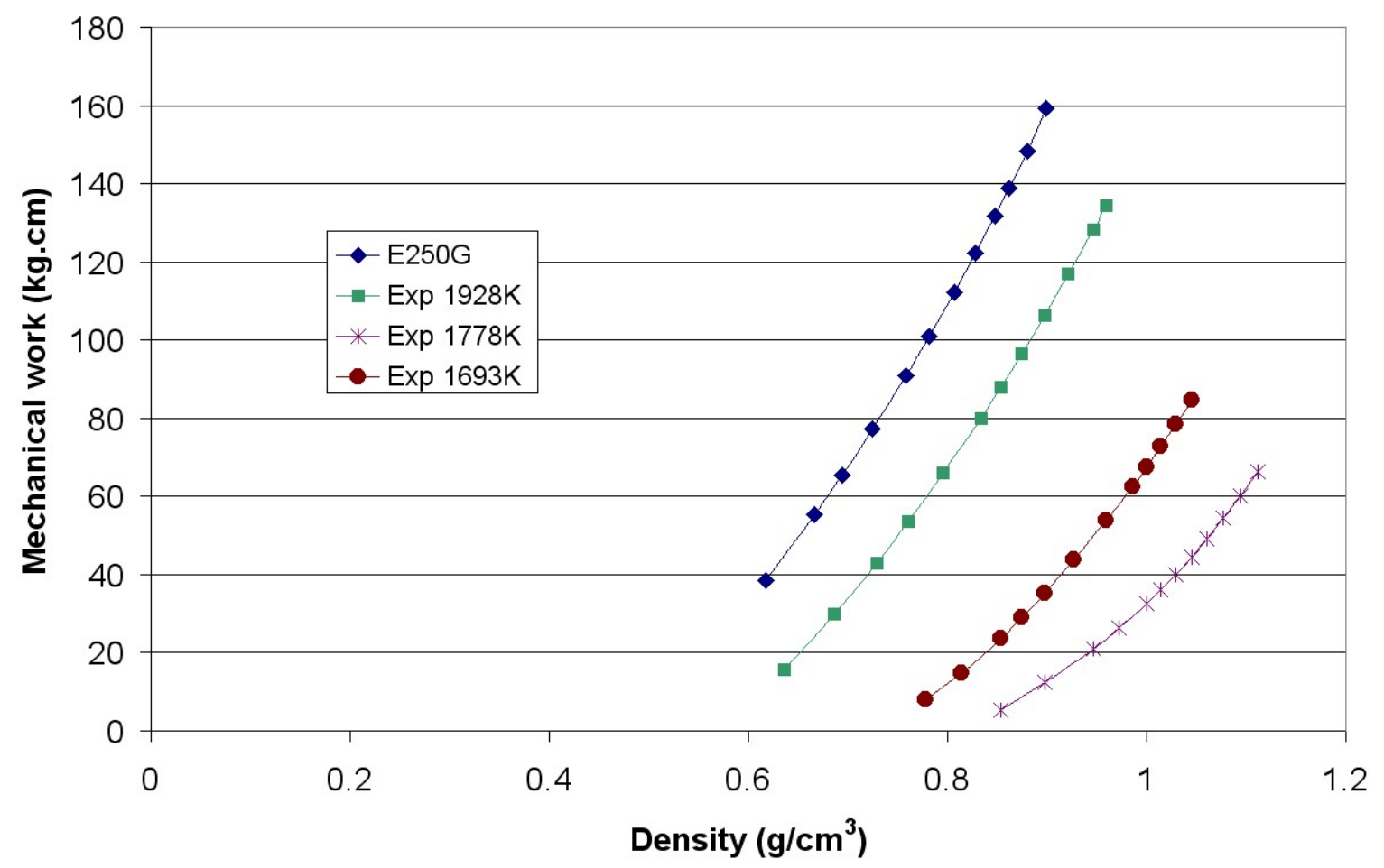

Figure 11: Mechanical work versus density for various experimental carbon black samples $\left(\mathrm{CH}_{4}=10.5 \mathrm{NL} / \mathrm{min}, \mathrm{Ar}=31.5 \mathrm{NL} / \mathrm{min}\right)$ obtained at different temperatures and for the reference E250G

It is also interesting to measure the conductivity of the carbon black samples under pressure (Figure 12). This can inform about the conductive capability of the carbon black [22]. Three experimental samples are represented for three temperatures (1928K, 1778K, 1693K) along 
with E250G. For a given carbon black, increasing the density improves the conductivity because the contact area between the particles increases. E250G shows the best conductivity for a given density: the resistiviy is $0.055 \mathrm{Ohm} . \mathrm{cm}$ for a density of $0.8 \mathrm{~g} / \mathrm{cm}^{3}$ whereas it is $0.11 \mathrm{Ohm} . \mathrm{cm}$ for the sample from run 5. A conductive carbon black has a good conductivity even for low density. The experimental sample from run 5, obtained at the highest temperature, shows the closest behaviour with the commercial reference. For lower temperatures, the resistivity is even higher. It seems that high temperatures favour the conductivity. Poly-aromatic hydrocarbons adsorbed at the carbon black surface in the case of the experimental samples could also explain why a lower conductivity is measured. E250G has the highest conductivity and the best structure. A high structure should improve the conductivity since the probability of contact between the carbon particles is greater [23].

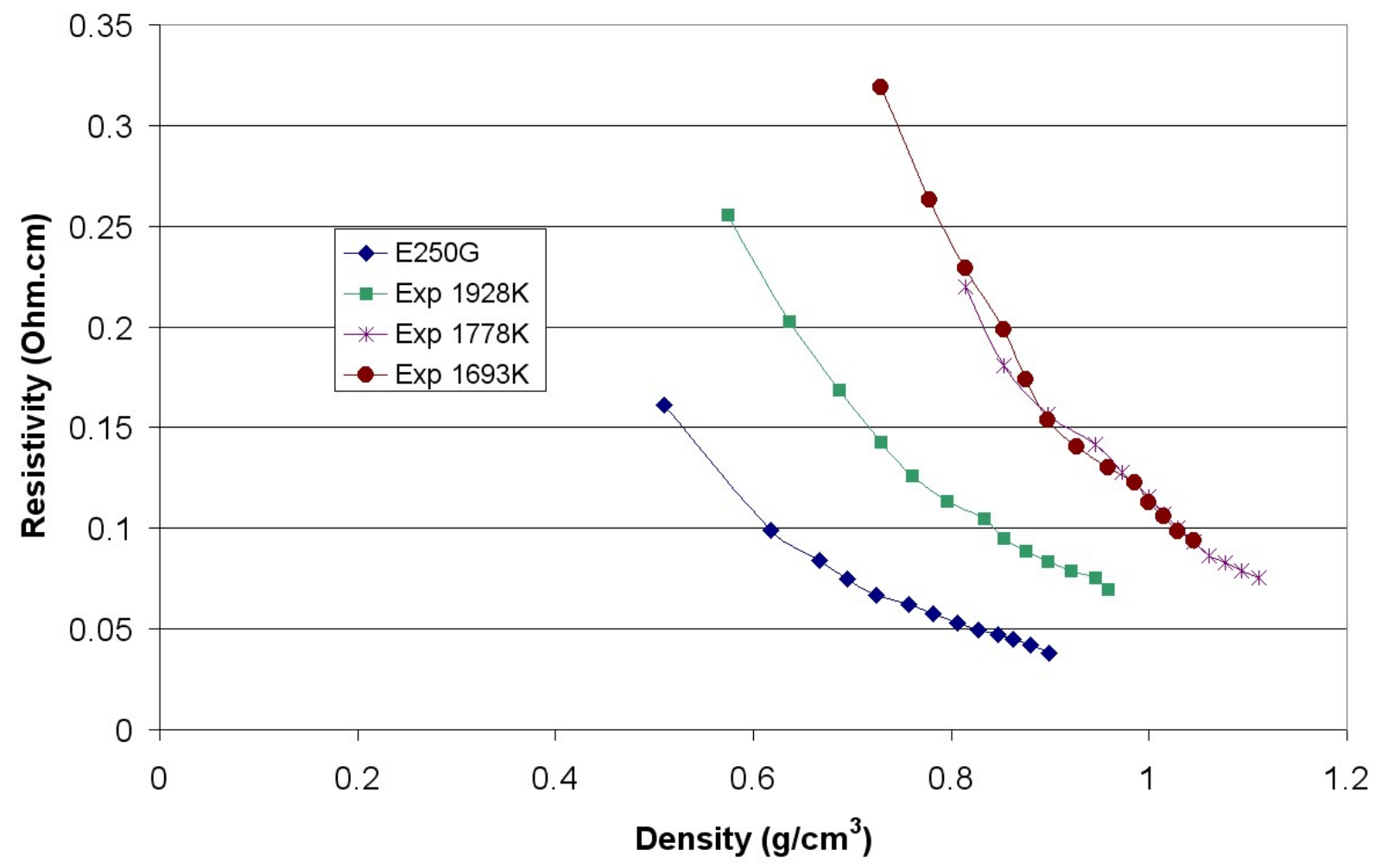

Figure 12: Resistivity versus density for various experimental carbon black samples $\left(\mathrm{CH}_{4}=10.5 \mathrm{NL} / \mathrm{min}, \mathrm{Ar}=31.5 \mathrm{NL} / \mathrm{min}\right)$ obtained at different temperatures and for the reference E250G 
Conductive carbon black is used in polymers to decrease their electrical resistivity. The higher the structure, the smaller the required load of carbon black to reach a given conductivity. Compounding tests [24] have been carried out for the carbon black sample from run 5. For a 25\% load (mass) in High Density Poly Ethylene, the matrix resistivity was 4200 Ohm.cm compared to 6 Ohm.cm for E250G. Both a lower structure and conductivity thus lead to weaker performances of the compounded polymer when a conductive polymer application is targeted.

\section{Conclusion}

A pilot-scale solar reactor $\left(50 \mathrm{~kW}_{\text {th }}\right)$ was developed and operated for the co-production of carbon black and hydrogen. Methane was dissociated in tubular sections at temperatures ranging from $1608 \mathrm{~K}$ to $1928 \mathrm{~K}$. A detailed analysis of carbon blacks obtained was presented in this paper. TEM imaging, Raman spectroscopy, BET analysis and measurements of conductivity under compression were carried out.

Crystallite lengths in the 1-4 $\mathrm{nm}$ range were observed by TEM imaging, which is in agreement with estimated values from Raman spectroscopy. The temperature of methane dissociation is the main parameter that influences the specific surface area of carbon (in the range $60-100 \mathrm{~m}^{2} / \mathrm{g}$ ). The comparison with the properties of a commercial conductive carbon black shows that the sample obtained at the highest temperature (1928K) has a structure and a conductivity approaching this reference.

According to the obtained specific surface area, applications of the solar-synthesized carbon black in the tyre industry appear possible. Further improvements of carbon properties can also be anticipated by adjusting and optimising the operating conditions and by applying pre- or post- treatments (e.g. oxidation). With special attention on the carbon black production process, applications related to conductive carbon black seem reachable. Tests should be 
carried out in the targeted end use applications to get more feedback. Finally, the solar process should be seriously considered as an environmentally friendly option for a clean coproduction of valuable carbon black and hydrogen.

\section{Acknowledgements:}

This study was funded by the European Project Solhycarb (2006-2010, Contract SESCT2006-19770). The authors wish to thank Jean-Louis Sans, Olivier Prévost and Marc Garrabos for their technical support during the solar reactor manufacturing and operation.

\section{References:}

[1] Lockwood FC, Van Niekerk JE. Parametric Study of a Carbon Black Oil Furnace. Combustion and Flame 1995; 103(1-2):76-90.

[2] Reg Adams. Booming world carbon black demand but price rises fail to keep pace with rising gas \& feedstock costs. Focus on Pigments 2007; 3:1-2.

[3] Wyss J, Martinek J, Kerins M, Dahl JK, Weimer A, Lewandowski A, et al. Rapid Solarthermal Decarbonization of Methane in a Fluid-wall Aerosol Flow Reactor - Fundamentals and Application, International journal of chemical reactor engineering 2007; 5, A69.

[4] Fulcheri L, Schwob Y. From methane to hydrogen, carbon and water. International Journal of Hydrogen Energy 1995; 20(3):197-202.

[5] Fulcheri L, Probst N, Flamant G, Fabry F, Grivei E, Bourrat X. Plasma processing: a step towards the production of new grades of carbon black. Carbon 2002; 40(2):169-176.

[6] Gonzalez-Aguilar J, Dème I, Fulcheri L, Flamant G, Gruenberger TM, Ravary B. Comparison of simple particle-radiation coupling models applied on a plasma black process. Plasma Chem Plasma Process 2004; 24(4):603-623. 
[7] Moreno-Couranjou M., Monthioux M., Gonzalez-Aguilar J., Fulcheri L., A non-thermal plasma process for the gas phase synthesis of carbon nanoparticles. Carbon 2009; 47:23102321.

[8] Maag G, Zanganeh G, Steinfeld A. Solar thermal cracking of methane in a particle-flow reactor for the co-production of hydrogen and carbon. International Journal of Hydrogen Energy $2009 ; 34: 7676-7685$.

[9] Lee KL, Lee SY, Han GY, Lee BK, Lee TJ, Jun JH, et al. Catalytic decomposition of methane over carbon blacks for $\mathrm{CO}_{2}$-free hydrogen production. Carbon 2004; 42:2641-2648.

[10] Rodat S, Abanades S, Sans JL, Flamant G. A pilot-scale solar reactor for the production of hydrogen and carbon black from methane splitting. International Journal of Hydrogen Energy 2010; 35(15):7748-7758.

[11] Hirsch D, Steinfeld A. Solar hydrogen production by thermal decomposition of natural gas using a vortex-flow reactor. International Journal of Hydrogen Energy 2004; 29(1):47-55. [12] Donnet JB, Bansal RC, Wang MJ. Carbon Black, Second edition, Revised and expanded, Science and Technology, Marcel Dekker, New York; 1993.

[13] Larouche N, Stansfield BL. Classifying nanostructured carbons using graphitic indices derived from Raman spectra. Carbon 2010; 48:620-629.

[14] Probst N, Grivei E. Structure and electrical properties of carbon black. Carbon 2002; 40(2):201-205.

[15] Sadezky A, Muckenhuber H, Grothe H, Niessner R, Poschl U. Raman microspectroscopy of soot and related carbonaceous materials: Spectral analysis and structural information. Carbon 2005; 43:1731-1742.

[16] Lorentzou S, Pagkoura C, Zygogianni A, Kastrinaki G, Konstandopoulos AG. Catalytic nano-structured materials for next generation Diesel particulate filters. SAE Tech. Paper No. 2008-01-0417, 2008. 
[17] Fulcheri L, Schwob Y, Flamant G. Comparison of new carbon nanostructures produced by thermal plasma with industrial Carbon black grades. Journal de Physique III (France) $1997 ; 7: 491-503$.

[18] Knight DS, White WB. Characterization of diamond films by Raman spectroscopy. J. Materials Research 1989; 4:386-393.

[19] Tuinstra F, Koeinig JL. Raman spectrum of graphite. J. Chem. Phys. 1970; 53,11261130.

[20] Parkash S. Petroleum Fuels Manufacturing Handbook, McGraw Hill Professional; 2009.

[21] Buxbaum G, Pfaff G, Industrial Inorganic Pigments, Third, Completely Revised Edidtion, Wiley-VCH; 2005.

[22] Pantea D, Darmstadt H, Kaliaguine S, Roy C. Electrical conductivity of conductive carbon blacks: influence of surface chemistry and topology. Applied surface science 2003; 217:181-193.

[23] Sanchez-Gonzalez J, Macias-Garcia A, Alexandre-Franco MF, Gomez-Serrano V. Electrical conductivity of carbon blacks under compression. Carbon 2005; 43:741-747.

[24] Probst N, Van Bellingen C, Van den Bergh H. Compounding with conductive carbon black. Plastics, Additives and Compounding 2009; 11(3):24-27. 